\title{
Nuclear Receptors and
}

\section{Neuroinflammation in Schizophrenia}

\author{
Shan-Yuan Tsai ${ }^{\mathrm{a}-\mathrm{c}}$ Vibeke S. Catts ${ }^{\mathrm{a}-\mathrm{c}}$ Janice M. Fullerton ${ }^{\mathrm{a}, \mathrm{b}, \mathrm{d}}$ Susan M. Corley ${ }^{\mathrm{e}}$ \\ Stuart G. Fillman ${ }^{\mathrm{a}-\mathrm{c}}$ Cynthia Shannon Weickert ${ }^{\mathrm{a}-\mathrm{c}}$ \\ a Schizophrenia Research Institute, Sydney, NSW, Australia; b Neuroscience Research Australia, Sydney, NSW, \\ Australia; 'School of Psychiatry, University of New South Wales, Sydney, NSW, Australia; d School of Medical \\ Sciences, University of New South Wales, Sydney, NSW, Australia; ' Systems Biology Initiative, School of \\ Biotechnology and Biomolecular Sciences, University of New South Wales, Sydney, NSW, Australia
}

\section{Keywords}

Vitamin D receptor $\cdot$ RXR $\cdot$ RAR $\cdot$ NR4A $\cdot$ Inflammation .

Schizophrenia Dorsolateral prefrontal cortex

\begin{abstract}
Introduction: Several nuclear receptor family members have been associated with schizophrenia and inflammation. Vitamins $A$ and $D$ exert anti-inflammatory actions, but their receptors (mainly nuclear receptors) have not been extensively studied in either schizophrenia brains or in association with neuroinflammation. We examined the expression of vitamin A (RARs and RXRs) and vitamin D and protein disulphide-isomerase A3 (PDIA3) receptors, as well as nuclear orphan receptors (NR4As), in the context of elevated cytokine expression in the dorsolateral prefrontal cortex (DLPFC). Methods: mRNA levels of nuclear receptors were measured in DLPFC tissues via RT-qPCR. ANCOVAs comparing high inflammation schizophrenia, low inflammation schizophrenia and low inflammation control groups were performed. Results: RARG, RXRB, NR4A1 and NR4A3 transcripts showed significant differential expression across the three groups (ANCOVA $p=0.02-0.001$ ). Post hoc testing revealed significant reductions in RARG expression in schizophrenia with
\end{abstract}

\section{KARGER}

(C) 2018 S. Karger AG, Basel

E-Mail karger@karger.com

www.karger.com/mnp low inflammation compared to schizophrenia with high inflammation and to controls, and RXRB mRNA was significantly reduced in schizophrenia with low inflammation compared to controls. NR4A 1 and NR4A3 mRNAs were decreased in schizophrenia with high inflammation compared to schizophrenia with low inflammation, with NR4A1 also significantly different to controls. Conclusion: In schizophrenia, changes in nuclear receptor mRNA levels involved with mediating actions of vitamin A derivatives vary according to the inflammatory state of brains.

(c) 2018 S. Karger AG, Basel

\section{Introduction}

Schizophrenia is a debilitating mental illness affecting approximately $1 \%$ of the world's population. Whilst the primary cause is still uncertain, many genetic polymorphisms and environmental perturbations have been implicated in increased risk of schizophrenia. One of the main molecular mechanisms whereby genes and environments converge to mediate risk is in the control of gene expression. Several transcription factors are altered in the brains of people with schizophrenia, including

Cynthia Shannon Weickert

Neuroscience Research Australia, Margarete Ainsworth Building 139 Barker St

Randwick, NSW 2031 (Australia)

E-Mail c.weickert@neura.edu.au 
members of the nuclear receptor superfamily, such as the expression of oestrogen receptor mRNA $[1,2]$, and the mRNA and protein levels of the glucocorticoid receptor $[3,4]$. Changes in ligands (low oestrogen levels and increased stress hormone) appear to exaggerate symptoms of schizophrenia [5-8]. Vitamin D is another ligand with brain responsive nuclear receptors, and both very low and very high prenatal exposure to vitamin $\mathrm{D}$ is associated with a two-fold increased risk of later developing schizophrenia or schizophrenia-like behaviour [9-11]. However, despite compelling evidence of the neurodevelopmental role of vitamin D [9], the extent to which vitamin D receptors (VDRs) may be altered in the brain of people who have already developed schizophrenia has not been examined.

Epidemiological studies have shown that maternal malnourishment and vitamin deficiencies due to famine lead to an increased risk of schizophrenia in the offspring $[12,13]$. Additionally, higher rates of schizophrenia are observed amongst people born in winter and spring, though the associated higher rates of maternal infection in these seasons and vitamin D deficiency due to reduced sunlight cannot easily be disentangled [14]. Low levels of vitamin $\mathrm{D}$ could be caused by a number of factors, including dietary insufficiency, reduced exposure to sunlight [14], or reduced enzyme activity of $1 \alpha$-hydroxylase, the enzyme responsible for formation of the active vitamin [15]. In addition to these perinatal risk factors, low circulating vitamin $\mathrm{D}$ levels have been found in people with schizophrenia [19], and associated with symptom severity [20] and with general decreased cognitive function in adulthood $[21,22]$ and it is possible that abnormalities extend to include VDRs in the brain. To our knowledge, there have been no studies examining the expression of VDR in the brains of people with schizophrenia to date.

There are two types of VDRs: the cytosolic/nuclear VDR, and the VDR at the cell membrane, which is a rapid response steroid-binding receptor, also known as the protein disulphide-isomerase A3 (PDIA3). Both vitamin $\mathrm{D}$ and VDR have been shown to have neuroprotective qualities [23-25]. VDR is expressed in both glia and neurons in numerous regions of the human brain including the prefrontal cortex [15]. VDR is predominantly present in the cytoplasm. Once bound by vitamin $\mathrm{D}$, the complex translocates to the nucleus where it acts to increase or decrease gene expression [26]. Once the membrane form of VDR, PDIA3, is bound by vitamin D [27], PDIA3 elicits a fast uptake of calcium and phosphorus into cells [28]. Few studies have directly examined genetic association between VDR or PDIA3 and schizophrenia, and these have been of very limited sample size (i.e., $<200$ cases) [29-31]. More recently, a genome-wide association study of nearly 37,000 individuals with schizophrenia [32] provides significant evidence of association of a locus on chromosome 6 containing the retinoid $\mathrm{X}$ receptor $\mathrm{B}$ gene (RXRB), as well as nominal evidence of association of a number of other retinoid receptor genes including RARG, VDR, and PDIA3 ( $p<6.8 \mathrm{E}-5)$. Thus, it is possible that interactions between genetic risk variants and environmental exposures, which are thus far poorly studied, result in disrupted receptor signalling and increased risk of schizophrenia.

VDR can heterodimerise with other nuclear receptors and mediate transcriptional controls through binding to vitamin A receptors (retinoid receptors), and through binding to direct nucleotide sequences [33] and DNA response elements [34]. Retinoic acid is a derivative of vitamin A and it is important for growth, differentiation, and homeostasis within the brain [35] and may have neuroprotective actions after brain trauma [36-38]. The three members of the retinoic acid receptor family (RARA, RARB, and RARG) have highly similar structures and bind to all-trans retinoic acid, the active form of vitamin A $[39,40]$. In contrast, the three retinoid X receptors (RXRA, RXRB, and RXRG) are indirectly activated by all-trans retinoic acid, but do not directly bind the ligand $[39,40]$. VDR can dimerise with RXRs to regulate transcription, and VDR has been shown to dimerise more readily to RXRA than to the other RXRs [41, 42].

We have previously found RXRB mRNA, as well as another group of nuclear receptor superfamily members, NR4A1 and NR4A2, to be decreased in schizophrenia patients compared to controls [43]. Extending from our previous study, we now investigated the possible relationship these decreases may have to any putative change in VDRs, and to markers of inflammation. We previously found a subset of individuals with schizophrenia with elevated expression of a number of inflammatory markers in the dorsolateral prefrontal cortex (DLPFC) [44, 45] and the orbital frontal cortex [46], which we have termed a "high neuroinflammation" group. Further, we demonstrated that increased cytokines are associated with elevated microglia density [44] and reduced grey matter volume in the frontal cortex [46] of individuals with schizophrenia. This is consistent with previous studies showing that maternal immune activation predisposes to schizophrenia $[47,48]$ and increased activated microglia, a key source of cytokines in the brain, in people with schizo- 
Table 1. Control and schizophrenia cohort demographics

\begin{tabular}{|c|c|c|c|c|c|c|}
\hline & Control group & $\begin{array}{l}\text { Schizophrenia } \\
\text { group }\end{array}$ & C-LO group & S-LO group & S-HI group & $\begin{array}{l}p \text { value across } \\
\text { C-LO, S-LO } \\
\text { and S-HI groups }\end{array}$ \\
\hline Number of cases & $\begin{array}{l}\text { Healthy } \\
\text { controls }=37\end{array}$ & $\begin{array}{l}\text { Schizophrenia }=30 \\
\text { Schizoaffective }=7\end{array}$ & 33 & 23 & 14 & - \\
\hline Age, years & $51.1(18-78)$ & $51.3(27-75)$ & $50.8(21-78)$ & $49.7(27-75)$ & $53.93(30-68)$ & 0.666 \\
\hline Gender & $\mathrm{F}=7, \mathrm{M}=30$ & $\mathrm{~F}=13, \mathrm{M}=24$ & $\mathrm{~F}=7, \mathrm{M}=26$ & $\mathrm{~F}=7, \mathrm{M}=16$ & $\mathrm{~F}=6, \mathrm{M}=8$ & 0.314 \\
\hline Hemisphere & $\mathrm{L}=14, \mathrm{R}=23$ & $\mathrm{~L}=20, \mathrm{R}=17$ & $\mathrm{~L}=12, \mathrm{R}=21$ & $\mathrm{~L}=13, \mathrm{R}=10$ & $\mathrm{~L}=7, \mathrm{R}=7$ & 0.309 \\
\hline $\mathrm{pH}$ & $\begin{array}{l}6.66 \pm 0.30 \\
(5.84-7.19)\end{array}$ & $\begin{array}{l}6.61 \pm 0.30 \\
(5.69-7.09)\end{array}$ & $\begin{array}{l}6.68 \pm 0.30 \\
(5.84-7.19)\end{array}$ & $\begin{array}{l}6.75 \pm 0.23 \\
(6.19-7.09)\end{array}$ & $\begin{array}{l}6.39 \pm 0.28 \\
(5.69-6.82)\end{array}$ & 0.001 \\
\hline Post-mortem interval, h & $\begin{array}{l}24.8 \pm 10.97 \\
(6.5-50)\end{array}$ & $\begin{array}{l}28.5 \pm 13.77 \\
(5-72)\end{array}$ & $\begin{array}{l}24.5 \pm 11.00 \\
(6.5-50)\end{array}$ & $\begin{array}{l}30.5 \pm 10.90 \\
(10-50)\end{array}$ & $\begin{array}{l}25.1 \pm 17.44 \\
(5-72)\end{array}$ & 0.191 \\
\hline RNA integrity number (RIN) & $\begin{array}{l}7.3 \pm 0.57 \\
(6.0-8.4)\end{array}$ & $\begin{array}{l}7.3 \pm 0.58 \\
(6.2-8.4)\end{array}$ & $\begin{array}{l}7.3 \pm 0.59 \\
(6.0-8.4)\end{array}$ & $\begin{array}{l}7.34 \pm 0.58 \\
(6.3-8.3)\end{array}$ & $\begin{array}{l}7.2 \pm 0.58 \\
(6.2-8.4)\end{array}$ & 0.610 \\
\hline Manner of death & Natural $=37$ & $\begin{array}{l}\text { Natural }=29 \\
\text { Suicide }=8\end{array}$ & Natural $=33$ & $\begin{array}{l}\text { Natural }=16 \\
\text { Suicide }=7\end{array}$ & $\begin{array}{l}\text { Natural }=13 \\
\text { Suicide }=1\end{array}$ & - \\
\hline Age of onset, years & - & $23.7 \pm 6.07$ & - & $24.3 \pm 6.5$ & $22.8 \pm 5.34$ & - \\
\hline Duration of Illness, years & - & $27.6 \pm 13.8$ & - & $25.5 \pm 14.8$ & $31.1 \pm 11.8$ & - \\
\hline Mean daily chlorpromazine, $\mathrm{mg}$ & - & $692 \pm 502$ & - & $603 \pm 407$ & $837 \pm 618$ & - \\
\hline $\begin{array}{l}\text { Last recorded chlorpromazine } \\
\text { dose, } \mathrm{mg}\end{array}$ & - & $542 \pm 374$ & - & $474 \pm 360$ & $679 \pm 381$ & - \\
\hline
\end{tabular}

C-LO, control low inflammation; S-LO, schizophrenia low inflammation; S-HI, schizophrenia high inflammation; F, female, M, male; L, left; R, right; \pm , standard deviation.

phrenia $[49,50]$. As vitamin D and vitamin A possess anti-inflammatory properties, and as nuclear receptor family members have reduced expression in the context of neuroinflammation, we hypothesised that decreased gene expressions of VDR, PDIA3, retinoid receptors, and NR4A receptors will be exacerbated in individuals with schizophrenia who also have evidence of neuroinflammation.

\section{Materials and Methods}

\section{Subjects}

Brain tissue was provided by the New South Wales Brain Tissue Resource Centre, under ethical approval by the Human Research Ethics Committee at the University of New South Wales (HREC 12435). Brains from 37 cases (30 individuals diagnosed with schizophrenia and 7 with schizoaffective disorder) and 37 matched control individuals were selected. Case and control subjects were matched at a group level on brain tissue $\mathrm{pH}$, age, post-mortem interval (PMI), hemisphere, and gender, and tissue from the DLPFC was dissected as previously described [51]. Low and high inflammation groups were determined based on a two-step cluster analysis of gene expression of markers of inflammation: IL1B, IL6, IL8, and serine protease inhibitor A3 [44]. The high inflammation control group was omitted in the current study due to a small sample size $(n=4)$, precluding meaningful statistical analysis.

Nuclear Receptors and

Neuroinflammation
Tissue Processing, RNA Extraction, and cDNA Synthesis

Cortical tissues were crudely pulverised over dry ice, and 300 mg used for extraction of total RNA using TRIzol Reagent (Life Technologies Inc., Grand Island, NY, USA), as previously described [51]. The quantity and quality of RNA was determined by spectrophotometer (Nanodrop ND-1000, Thermo Scientific) and Agilent Bioanalyzer 2100 (Agilent Technologies, Palo Alto, CA, USA). Three rounds of 3- $\mu$ g total RNA was used for cDNA synthesis, using either SuperScript ${ }^{\circledR}$ II or III First-Strand Synthesis System for RT-PCR (Life Technologies, Carlsbad, CA, USA). A seven-point serial dilution standard curve was created using 3 randomly selected schizophrenia cases and 3 randomly selected control cases.

\section{Real-Time Quantitative Polymerase Chain Reaction}

mRNA for each gene of interest was amplified from cDNA using TaqMan ${ }^{\circledR}$ Universal PCR Master Mix and the following Taqman probes (Thermo Fisher Scientific): VDR (Hs01045840_m1), PDIA3 (Hs00607126_m1; spanning exons 1-2 of most common isoforms); and the assays published in Corley et al. [43] RARA (Hs00940446_m1), RARB (forward/reverse: GCAGAGCGTGTAATTACCTTGAA/GTGAGATGCTAGGACTGTGCTCT), RARG (Hs01559234_m1), RXRA (Hs01067640_m1), RXRB (Hs00232774_m1), RXRG (Hs00199455_m1), NR4A1 (Hs00374226_m1), NR4A2 (Hs00428691_m1), and NR4A3 (Hs00545009_g1). mRNA expression was measured in triplicate using the 7900HT Fast Real Time PCR System (Applied Biosystems, Inc.). Florescent intensity values were normalised against the 


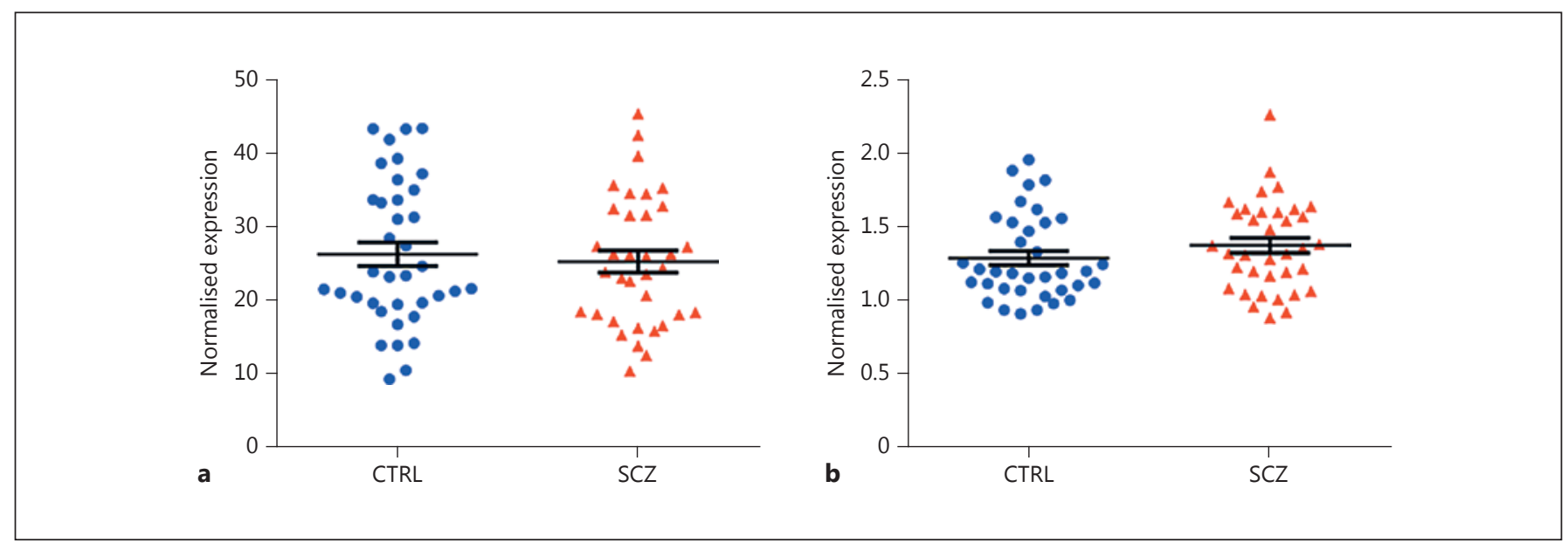

Fig. 1. Normalised mRNA expression levels by diagnosis of vitamin D receptor (VDR) (a) and protein disulphide-isomerase A3 (PDIA3) (b). mRNA expression for each gene is normalised to the geometric mean of 4 housekeeper genes, and plotted on the $y$ axis. Individual data points for control subjects (CTRL; VDR: $n=37$, PDIA3: $n=36$ ) are indicated with circles, and individual data points for schizophrenia subjects (SCZ; VDR: $n=35$, PDIA3: $n=$ 36) are indicated with triangles. Mean values for each group are represented by a horizontal line, and the error bars indicate the standard error of mean. There were no significant differences in expression between diagnostic groups. geometric mean for four housekeeping genes that did not differ in expression between diagnostic groups [51], namely: ubiquitin $\mathrm{C}$ (Hs00824723_m1), glyceraldehyde 3-phosphate dehydrogenase (Hs99999905_m1), beta-actin (Hs99999903_m1), and TATAbinding protein (Hs00427620_m1).

\section{Statistical Analysis}

All data were analysed using SPSS version 23. Subjects whose normalised expression values fell outside two standard deviations from the means were removed (average $n=3$ per gene). Normalised expression values were tested for normality via the Kolmogorov-Smirnov test, and variables significantly deviating from a normal distribution were transformed via log or inverse transform to achieve Gaussian distributions. $\chi^{2}$ tests were performed to determine whether sex and hemisphere were evenly distributed across the inflammation diagnostic groups. Normalised expression values for PDIA3 and NR4A3 were inverse transformed and RARG, RXRA, and RXRB results were transformed using log function to achieve Gaussian distributions within the inflammation diagnostic groups. Analyses of diagnostic group differences for all genes excluding VDR and PDIA3 mRNAs are previously described [43]. Pearson correlation tests were conducted between normalised gene expression and age, PMI, pH and RIN - variables showing significant correlations $(p<0.05)$ were included as covariates in downstream analyses. ANCOVAs were conducted using gene expression as the dependant variable and group as fixed factor plus relevant covariates, where $p$ values $<0.05$ were considered significant. Post hoc testing by the Fisher least significant difference was performed for genes with significant ANCOVA results. All transcripts of interest were analysed for hemisphere and inflammation $\times$ diagnostic group differences.

\section{Results}

A cohort description and relevant demographics of subjects included in this study are presented in Table 1. All analyses used mRNA extracted from either the left or right hemisphere, with the relative breakdown being $56.5 \%$ for the left and $43.5 \%$ for the right hemisphere in the low inflammation schizophrenia group, and an equal $50 \%$ left:right in the high inflammation schizophrenia group. In the low inflammation control group, $63.6 \%$ of samples were from the right hemisphere.

\section{Correlation Analysis}

Significant correlations between normalised gene expression and age, PMI or RNA integrity (RIN) were observed, whereby expression of the 3 NR4A genes correlated with age ( $p=0.003-0.000002)$, the 3 RXRs and RARG and PDIA3 gene expression correlated with RIN $(p=0.012-0.00003)$, and some correlation with PMI were observed for RARA and RXRG ( $p=0.031-0.032)$. Tissue $\mathrm{pH}$ differed amongst inflammation diagnostic groups $(p=0.001)$. Therefore, $\mathrm{pH}$ was included as a covariate in all statistical analyses, and age, PMI, and RIN were included in each ANCOVA where appropriate.

\section{Hemisphere, Gender and Diagnostic Effects}

VDR and PDIA3 mRNA expressions were not significantly altered between diagnostic groups (Fig. 1), and 

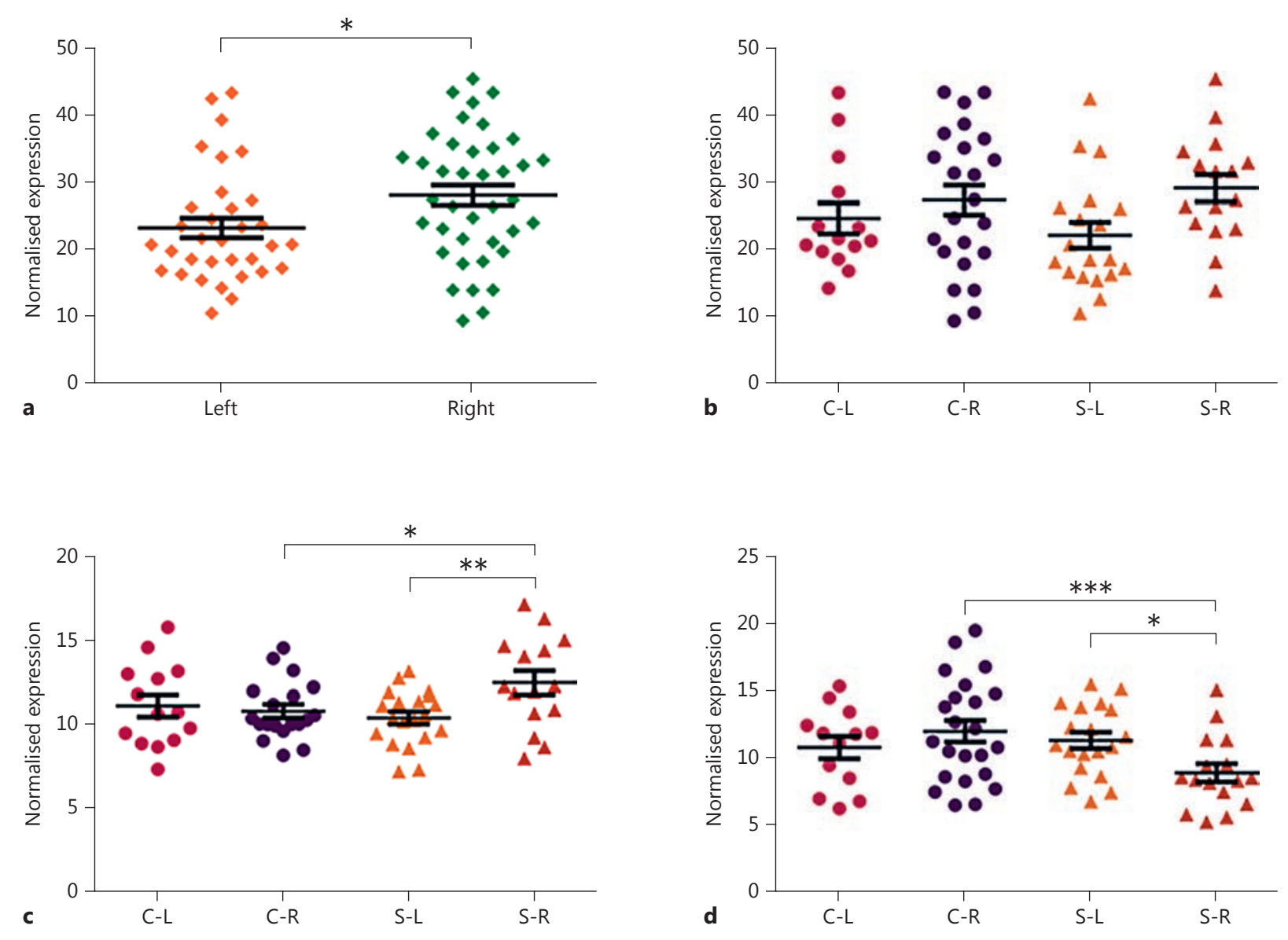

Fig. 2. Hemisphere effects on normalised mRNA expression. a Expression level of vitamin D receptor (VDR) was significantly higher in the right hemisphere compared to the left hemisphere. Individual data points for left hemisphere subjects (left; $n=33$ ) are indicated in orange, and individual data points for right hemisphere subjects (right; $n=39$ ) are indicated in green. Interactions between hemisphere and diagnosis for $\operatorname{VDR}(\mathbf{b}), \operatorname{RARB}(\mathbf{c})$, and NR4A2 (d). mRNA expression for each gene is normalised to the geometric mean of 4 housekeeper genes, and plotted on the $y$ axis.

there were no differences in expression between sexes. Differential expression of the other nuclear receptors in control and schizophrenia diagnostic groups has previously been described [43]. There was no significant difference between the two hemispheres in the mRNA expression of PDIA3, but the expression of VDR mRNA in the right hemisphere was higher than that in the left $(\mathrm{F}[1$, $70]=5.216, p=0.025$ ) (Fig. 2a, b). We found an interaction effect between diagnosis and hemisphere in mRNA expression of RARB $(\mathrm{F}[1,64]=5.228, p=0.026)$ and NR4A2 $(F[1,64]=5.090, p=0.027$; Fig. $2 c, d)$. The
Individual data points for control subjects (CTRL; VDR: $n=37$, RARB: $n=33$, NR4A2: $n=36$ ) are indicated with circles, and individual data points for schizophrenia subjects (SCZ; VDR, RARB, NR4A2: $n=35$ ) are indicated with triangles. C-L, control left hemisphere; C-R, control right hemisphere; S-L, schizophrenia left hemisphere; $\mathrm{S}-\mathrm{R}$, schizophrenia right hemisphere. Mean values for each group are represented by a horizontal line, and the error bars indicate the standard error of mean.

mRNA expression of RARB in the right hemisphere was significantly higher in schizophrenia compared to controls $(\mathrm{F}[1,64]=5.256, p=0.025)$, and in schizophrenia, it was significantly higher in the right compared to the left hemisphere $(\mathrm{F}[1,64]=8.155, p=0.006)$ (Fig. 2c). Conversely, the mRNA expression of NR4A2 in the right hemisphere was significantly lower in schizophrenia compared to controls $(F[1,64]=11.086, p=0.001)$, and in schizophrenia, it was significantly lower in the right compared to the left hemisphere $(\mathrm{F}[1,64]=6.182, p=$ 0.016; Fig. 2d). 
Table 2. ANCOVA of inflammatory subgroups

\begin{tabular}{|c|c|c|c|c|c|c|c|c|}
\hline $\begin{array}{l}\text { Gene } \\
\text { VDR }\end{array}$ & $\begin{array}{l}F \text { value } \\
\mathrm{F}(2,65)=0.088677\end{array}$ & $\begin{array}{l}p \text { value } \\
0.91525\end{array}$ & 26.293937 & $(33)$ & 24.74803 & $(22)$ & 27.929237 & (14) \\
\hline $\mathrm{PDIA}^{\mathrm{a}}$ & $F(2,63)=2.055666$ & 0.13651 & 1.22274501 & (32) & 1.26193475 & (22) & 1.52405802 & (14) \\
\hline RARA & $\mathrm{F}(2,62)=0.731938$ & 0.48509 & 2.224292 & (31) & 2.277531 & (22) & 2.326386 & (14) \\
\hline RXRA $^{b}$ & $\mathrm{~F}(2,61)=2.039639$ & 0.13885 & 1.204098 & (32) & 1.276 & (21) & 1.28783 & (13) \\
\hline RXRBb & $\mathrm{F}(2,63)=6.844120$ & 0.00204 & 1.78774 & (33) & 1.596858 & (21) & 1.750243 & (14) \\
\hline RXRG & $\mathrm{F}(2,60)=0.314212$ & 0.73156 & 8.558743 & (31) & 7.502494 & (22) & 9.179348 & (13) \\
\hline NR4A1/Nur77 & $F(2,62)=5.256636$ & 0.00778 & 4.531548 & (32) & 4.218707 & (22) & 2.717897 & (13) \\
\hline NR4A2/Nurr1 & $\mathrm{F}(2,62)=2.032560$ & 0.13964 & 11.687858 & (32) & 11.094222 & (21) & 9.069933 & (14) \\
\hline NR4A3/Nor $1^{\text {a }}$ & $\mathrm{F}(2,61)=4.084091$ & 0.02165 & 14.3157774 & (32) & 16.9093153 & (21) & 11.9401559 & (13) \\
\hline
\end{tabular}

Figures in bold indicate statistical significance. ${ }^{a}$ Inverse transformed data. ${ }^{b} \log _{10}$ transformed data. ${ }^{c}$ Figures in parentheses are numbers.

Table 3. ANCOVA of NR4A with chlorpromazine

\begin{tabular}{|c|c|c|c|c|c|c|}
\hline \multirow[t]{2}{*}{ Gene } & \multicolumn{2}{|l|}{ Daily } & \multicolumn{2}{|l|}{ Last recorded } & \multicolumn{2}{|l|}{ Lifetime } \\
\hline & $F$ value & $p$ value & $F$ value & $p$ value & $F$ value & $p$ value \\
\hline NR4A2/Nurr1 & $\mathrm{F}(1,32)=2.987074$ & 0.0936 & $\mathrm{~F}(1,28)=0.863169$ & 0.3608 & $\mathrm{~F}(1,32)=2.665712$ & 0.1123 \\
\hline NR4A3/Nor $1^{\text {a }}$ & $F(1,31)=8.278935$ & 0.0072 & $\mathrm{~F}(1,28)=9.971834$ & 0.0038 & $F(1,28)=9.971834$ & 0.0038 \\
\hline
\end{tabular}

Bold indicates statistical significance. ${ }^{\text {a }}$ Inverse transformed data.

Analysis of Inflammation $\times$ Diagnosis Group

Differences in Gene Expression

We found significant differences amongst the three inflammation/diagnosis groups in the mRNA expression levels of RARG, RXRB, NR4A1, and NR4A3 (ANCOVA $p=0.021-0.0019$ ) (Table 2; Fig. 3). There was no significant effect of inflammation/diagnostic group on the mRNA expression levels of VDR, PDIA3, RARA, RARB, RXRA, RXRG, or NR4A2 (ANCOVA $p$ values all $>0.13$ ).

To examine the directions of effect within each inflammatory subgroup, post hoc analysis revealed the RARG mRNA levels in the low inflammation schizophrenia (SLO) group to be significantly lower than the low inflammation control (C-LO) group ( $p=0.0023)$ and lower than the high inflammation schizophrenia (S-HI) group ( $p=$ 0.0018) (Fig. 3a). In a similar pattern to RARG, RXRB mRNA levels in the S-LO group were found to be signifi- cantly lower than the C-LO group ( $p=0.00045)$, but not significantly different from the S-HI group $(p=0.078)$ (Fig. 3b).

In contrast to the pattern of changes in retinoid receptor mRNAs, the nuclear orphan receptors showed overall reduced expression in the S-HI group. The mRNA expression levels of NR4A1 in the S-HI group was significantly lower than both the S-LO group $(p=0.0197)$ and the C-LO group ( $p=0.0019)$. The NR4A3 mRNA levels in the S-HI group were significantly lower than the S-LO group $(p=0.0062)$ and the C-LO group was also reduced at a trend level $(p=0.08)$.

\section{Relationship of Gene Expression to Illness Onset, \\ Duration or Medication Exposure}

In order to determine whether gene expression was related to illness duration, onset or medication exposure, we performed correlation analysis within the 


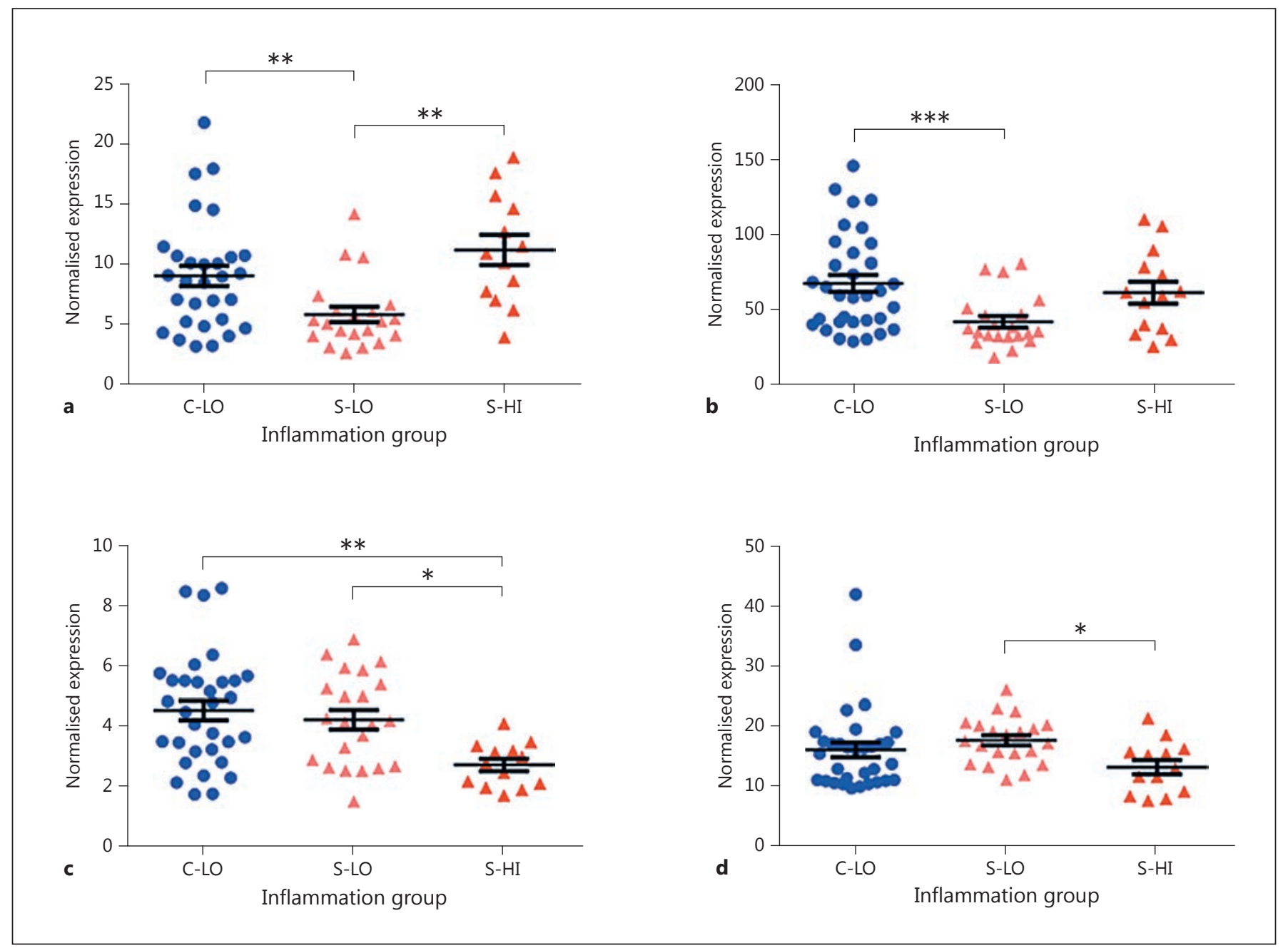

Fig. 3. Diagnosis $\times$ inflammatory group differences in normalised expression levels of RARG (a), RXRB (b), NR4A1 (c), and NR4A3 (d). mRNA expression for each gene is normalised to the geometric mean of 4 housekeeper genes, and plotted on the $y$ axis. Individual data points for control subjects from low inflammation group (C-LO; RARG: $n=31$, RXRB: $n=34$, NR4A1: $n=33$, NR4A3: $n=33$ ) are indicated with circles, and individual data

schizophrenia group only. VDR and PDIA3 did not correlate with age of onset, duration of illness and medication. Results for all other retinoid receptors and NR4A receptors have previously been described [43]. As we previously found negative correlations between the 3 NR4A receptors and medication (chlorpromazine equivalent) dose, we added antipsychotic medication dose as a covariate, finding that NR4A1 and NR4A3 expression remained significantly different between S-HI and S-LO group after accounting for medication dose (Table 3).

Nuclear Receptors and Neuroinflammation points for schizophrenia subjects from low and high inflammation groups (S-LO and S-HI, respectively; RARG: $n=22$ and 14, RXRB: $n=22$ and 15, NR4A1: $n=23$ and 14, NR4A3: $n=22$ and 14) are indicated with triangles. Mean values for each group are represented by a horizontal line, and the error bars indicate the standard error of mean. Note: the high inflammatory control group (C-HI) was omitted due to low sample number $(n=4)$.

\section{Discussion}

This unique study focuses on vitamin A and D in the human post-mortem schizophrenia brain from a neuroinflammation perspective. Several studies have shown the neuroprotective qualities of vitamin $\mathrm{D}[22,23,52]$. While the peripheral levels of vitamin $\mathrm{D}$ in individuals with schizophrenia have been extensively researched, this is the first study, to our knowledge, to measure the expression level of VDR in the brains of people with schizophrenia. We measured mRNA transcript levels of both the mem- 
brane-bound PDIA3 and cytosolic/nuclear VDR, but did not find any change in the overall level of either VDR mRNA with diagnosis. This suggests that the brains of individuals with schizophrenia may be able to respond normally to circulating vitamin D [23-25], although alterations as a result of alternative splicing of the primary transcript, or from altered translation or post-translational modification were not explored here. Since it has been proposed that increased vitamin D levels may have the potential to reduce the risk of schizophrenia [10], and we here showed that mRNA levels of VDRs are not changed in the brain of people with chronic schizophrenia, we would predict that augmenting vitamin $\mathrm{D}$ could be of potential preventative or therapeutic value as the intrinsic ability of the brain to respond to vitamin $\mathrm{D}$ may intact. Our results suggest that brain VDRs are synthesised within a normal range in people with schizophrenia and that this level does not vary depending on inflammatory status, suggesting that regardless of inflammation status, vitamin $\mathrm{D}$ augmentation in schizophrenia may be of benefit.

The literature suggests that increased levels of pro-inflammatory interleukins lead to a downregulation of retinoid receptors [53-55], whereas activation of retinoid receptors results in attenuation of inflammation [56-59]. This appears to be at odds with what we have observed in our study. Upon investigating the diagnostic inflammation groups, the mRNAs of two retinoid receptors, RXRB and RARG, as well as two orphan nuclear receptors, NR4A1 and NR4A3, were found to be significantly different amongst the 3 groups. With RXRB and RARG mRNAs being lower in the low inflammation schizophrenia group, it is unclear whether the change in expression of the retinoid receptors is leading to a change in inflammatory status or whether a change in inflammatory status is driving the changes in receptor expression. Previous work from our group has demonstrated reduced cognitive performance in individuals with schizophrenia with high inflammation [60], thus it appears that high inflammatory peripheral activity may have functional consequences for the brain. Here, our data do not support the hypothesis that decreased signalling via lower retinoid receptor levels is a likely contributor to the high inflammation in schizophrenia, but in fact we find increased retinoid receptors in high inflammation schizophrenia, perhaps reflecting an attempt to compensate for putative tissue damage during neuroinflammatory processes, as suggested by grey matter volume reductions [46] and elevated astrogliosis in those with schizophrenia and high inflammation [61].

NR4A1 and NR4A3 mRNAs showed a converse pattern to the retinoid receptors, with the high inflammation schizophrenia group showing decreased expression compared to the two low inflammation groups. Studies of macrophage and colon cancer cells have shown that NR4A receptors are typically upregulated with inflammation [62-64]. Additionally, overexpression of NR4A receptors in monocytes has been shown to reduce expression and production of pro-inflammatory cytokines [63]. This appears to be at odds with what we have observed in our cohort, although it may be explained by the relationship of NR4A receptors with aging: brain NR4A receptors decrease with age $[43,65,66]$ and neuroinflammation is elevated with age [67]; therefore, the decrease in NR4A receptors in the high inflammation schizophrenia group may be attributable to accelerated age-related changes associated with inflammation, the effect of which may be different in the brain compared to peripheral tissues. It may also be that the brain's ability to decrease retinoid receptors and increase NR4A receptors may reflect a lack of normal neuroinflammatory response, rendering the brain more vulnerable to deleterious effects of inflammation in those with schizophrenia.

In people with schizophrenia, the pathology of the left hemisphere is more severe than the right hemisphere [68-70]. In the same way as we see opposite patterns of retinoid receptor and NR4A receptors expression in the low inflammation groups in schizophrenia, we see opposite patterns in expression of these receptors between left and right hemispheres. NR4A2 expression is decreased in the right hemisphere in individuals with schizophrenia, whereas RARB is increased. This raises the question as to the regulation of transcription of these two receptor groups. It is known that RXRs heterodimerise with both RARs and NR4A receptors, but RARs and NR4A receptors do not heterodimerise to one another. Currently, there is no literature relating the RARs directly with the NR4As, in particular NR4A2, although a recent study has found that RARs regulate VDR transcription [71]. This hemispheric asymmetry supports findings of the left hemisphere being more pathologically impaired in schizophrenia compared to the right [68-70]. Thus, the decreased mRNA expression of VDR in the left hemisphere (regardless of diagnosis) could potentially contribute to reduced resilience of the left hemisphere in schizophrenia.

This work focuses on the overall mRNA expression level of the VDRs, retinoid receptors, and the NR4A receptors, but did not explore the levels of alternative spliced mRNA isoforms, protein levels or cellular location of these receptors or their wider interaction network, which is a limitation of the current study. 


\section{Conclusion}

We have shown that the mRNA expression of RARG and RXRB are reduced in schizophrenia individuals with low inflammation and this putative decreased signalling may suggest reduced retinoid-related neuroprotective actions in the absence of neuroinflammation in schizophrenia. In contrast, the mRNA expression of the 3 NR4A receptors is in the opposite pattern of change compared to RARG and RXRB. The reduction in NR4A1 and NR4A3 expression in the high inflammation schizophrenia group is consistent with the previously observed inverse relationship between NR4A receptors and age, as there is increased neuroinflammation with age. More studies on the role of nuclear receptors in neuroinflammation would be important steps towards potential targeted treatment of elevated inflammation in schizophrenia.

\section{Acknowledgements}

Tissues were received from the New South Wales Brain Tissue Resource Centre at the University of Sydney which is supported by the Schizophrenia Research Institute and National Institute of Alcohol Abuse and Alcoholism (NIH [NIAAA] R28AA012725).

\section{Statement of Ethics}

Brain tissue was provided by the New South Wales Brain Tissue Resource Centre, under ethical approval by the Human Research Ethics Committee at the University of New South Wales (HREC 12435).

\section{Disclosure Statement}

C.S.W. is a panel member of the Lundbeck Australia Advisory Board and is in collaboration with Astellas Pharma Inc., Japan. The authors have no conflicts of interest in relation to this specific work.

\section{Funding Sources}

This work was supported by Schizophrenia Research Institute (utilising infrastructure funding from the NSW Ministry of Health and the Macquarie Group Foundation), the University of New South Wales, and Neuroscience Research Australia. C.S.W. is a recipient of a National Health and Medical Research Council (Australia) Principal Research Fellowship (PRF) (\#1117079). S.-Y.T. is supported by The Cowled Postgraduate Research Scholarship in Brain Research. J.M.F. is supported by the Janette Mary O'Neil Fellowship and National Health and Medical Research Council (Australia) grant (\#1063960).

\section{References}

1 Weickert CS, Miranda-Angulo AL, Wong J, Perlman WR, Ward SE, Radhakrishna V, Straub RE, Weinberger DR, Kleinman JE: Variants in the estrogen receptor alpha gene and its mRNA contribute to risk for schizophrenia. Hum Mol Genet 2008; 17:2293-2309.

${ }_{2}$ Wong J, Weickert CS: Transcriptional interaction of an estrogen receptor splice variant and ErbB4 suggests convergence in gene susceptibility pathways in schizophrenia. J Biol Chem 2009;284:18824-18832.

-3 Sinclair D, Tsai SY, Woon HG, Weickert CS: Abnormal glucocorticoid receptor mRNA and protein isoform expression in the prefrontal cortex in psychiatric illness. Neuropsychopharmacology 2011;36:2698-2709.

-4 Sinclair D, Fullerton JM, Webster MJ, Weickert CS: Glucocorticoid receptor $1 \mathrm{~B}$ and 1C mRNA transcript alterations in schizophrenia and bipolar disorder, and their possible regulation by GR gene variants. PLoS One 2012; 7:e31720.

5 Seeman MV, Lang M: The role of estrogens in schizophrenia gender differences. Schizophr Bull 1990;16:185-194.

-6 Lindamer LA, Lohr JB, Harris MJ, Jeste DV: Gender, estrogen, and schizophrenia. Psychopharmacol Bull 1997;33:221-228.
Walker EF, Diforio D: Schizophrenia: a neural diathesis-stress model. Psychol Rev 1997; 104:667-685.

8 Corcoran C, Walker E, Huot R, Mittal V, Tessner K, Kestler L, Malaspina D: The stress cascade and schizophrenia: etiology and onset. Schizophr Bull 2003;29:671-692.

-9 McGrath JJ, Burne TH, Feron F, Mackay-Sim A, Eyles DW: Developmental vitamin D deficiency and risk of schizophrenia: a 10-year update. Schizophr Bull 2010;36:1073-1078.

10 McGrath J, Saari K, Hakko H, Jokelainen J, Jones P, Jarvelin MR, Chant D, Isohanni M: Vitamin D supplementation during the first year of life and risk of schizophrenia: a Finnish birth cohort study. Schizophr Res 2004;67: 237-245.

11 McGrath JJ, Eyles DW, Pedersen CB, Anderson C, Ko P, Burne TH, Norgaard-Pedersen B, Hougaard DM, Mortensen PB: Neonatal vitamin D status and risk of schizophrenia: a population-based case-control study. Arch Gen Psychiatry 2010;67:889-894.

12 St Clair D, Xu MQ, Wang P, Yu YQ, Fang YR, Zhang F, Zheng XY, Gu NF, Feng GY, Sham P, He L: Rates of adult schizophrenia following prenatal exposure to the Chinese famine of 1959-1961. JAMA 2005;294:557-562.
13 Susser ES, Lin SP: Schizophrenia after prenatal exposure to the Dutch Hunger Winter of 1944-1945. Arch Gen Psychiatry 1992;49: 983-988.

14 Schwartz PJ: Season of birth in schizophrenia: a maternal-fetal chronobiological hypothesis. Med Hypotheses 2011;76:785-793.

15 Eyles DW, Smith S, Kinobe R, Hewison M, McGrath JJ: Distribution of the vitamin D receptor and 1 alpha-hydroxylase in human brain. J Chem Neuroanat 2005;29:21-30.

16 Sequeira VB, Rybchyn MS, Tongkao-On W, Gordon-Thomson C, Malloy PJ, Nemere I, Norman AW, Reeve VE, Halliday GM, Feldman D, Mason RS: The role of the vitamin D receptor and ERp57 in photoprotection by 1a,25-dihydroxyvitamin D3. Mol Endocrinol 2012;26:574-582.

17 Feldman D, Malloy PJ: Mutations in the vita$\min \mathrm{D}$ receptor and hereditary vitamin D-resistant rickets. Bonekey Rep 2014;3:510.

18 Malloy PJ, Zhu WJ, Bouillon R, Feldman D: A novel nonsense mutation in the ligand binding domain of the vitamin $\mathrm{D}$ receptor causes hereditary 1,25-dihydroxyvitamin D-resistant rickets. Mol Genet Metab 2002;77:314318 .
Nuclear Receptors and

Neuroinflammation
Mol Neuropsychiatry 2017;3:181-191 DOI: $10.1159 / 000485565$ 
19 Itzhaky D, Amital D, Gorden K, Bogomolni A, Arnson Y, Amital H: Low serum vitamin D concentrations in patients with schizophrenia. Isr Med Assoc J 2012;14:88-92.

20 Graham KA, Keefe RS, Lieberman JA, Calikoglu AS, Lansing KM, Perkins DO: Relationship of low vitamin D status with positive, negative and cognitive symptom domains in people with first-episode schizophrenia. Early Interv Psychiatry 2015;9:397-405.

-21 Jorde R, Mathiesen EB, Rogne S, Wilsgaard T, Kjaergaard M, Grimnes G, Schirmer H: Vitamin $\mathrm{D}$ and cognitive function: the Tromso Study. J Neurol Sci 2015;355:155-161.

-22 Soni M, Kos K, Lang IA, Jones K, Melzer D, Llewellyn DJ: Vitamin D and cognitive function. Scand J Clin Lab Invest Suppl 2012;243: 79-82.

-23 Brewer LD, Thibault V, Chen KC, Langub MC, Landfield PW, Porter NM: Vitamin D hormone confers neuroprotection in parallel with downregulation of L-type calcium channel expression in hippocampal neurons. Neurosci 2001;21:98-108.

24 Kalueff AV, Eremin KO, Tuohimaa P: Mechanisms of neuroprotective action of vitamin D-3. Biochemistry (Mosc) 2004;69:738-741.

25 Jani A, Crockett S, Clarke M, Coleman B, Sims B: Vitamin D3-induced neuroprotection is dependent on system Xc activity. J Stem Cell Res Ther 2012;2:122.

-26 Wu-Wong JR, Nakane M, Ma JL, Dixon D, Gagne G: Vitamin D receptor (VDR) localization in human promyelocytic leukemia cells. Leuk Lymphoma 2006;47:727-732.

27 Nemere I, Garbi N, Hammerling GJ, Khanal $\mathrm{RC}$ : Intestinal cell calcium uptake and the targeted knockout of the 1,25D3-MARRS (membrane-associated, rapid response steroid-binding) receptor/PDIA3/Erp57. J Biol Chem 2010;285:31859-U31940.

-28 Farach-Carson MC, Nemere I: Membrane receptors for vitamin D steroid hormones: potential new drug targets. Curr Drug Targets 2003;4:67-76.

-29 Ozer S, Ulusahin A, Ulusoy S, Okur H, Coskun T, Tuncali T, Gogus A, Akarsu AN: Is vitamin D hypothesis for schizophrenia valid? Independent segregation of psychosis in a family with vitamin-D-dependent rickets type IIA. Prog Neuropsychopharmacol Biol Psychiatry 2004;28:255-266.

- 30 Yan J, Feng JN, Craddock N, Jones IR, Cook EH, Goldman D, Heston LL, Chen JS, Burkhart P, Li WY, Shibayama A, Sommer SS: Vitamin $D$ receptor variants in 192 patients with schizophrenia and other psychiatric diseases. Neurosci Lett 2005;380:37-41.

- 31 Handoko H, Nancarrow DJ, Mowry BJ, McGrath JJ: Polymorphisms in the vitamin D receptor and their associations with risk of schizophrenia and selected anthropometric measures. Am J Hum Biol 2006;18:415-417.
32 Ripke S, Neale BM, Corvin A, Walters JTR, Farh KH, Holmans PA, et al: Biological insights from 108 schizophrenia-associated genetic loci. Nature 2014;511:421-427.

33 Kato S, Sasaki H, Suzawa M, Masushige S, Tora L, Chambon P, Gronemeyer H: Widely spaced, directly repeated PuGGTCA elements act as promiscuous enhancers for different classes of nuclear receptors. Mol Cell Biol 1995;15:5858-5867.

34 Jimenez-Lara AM, Aranda A: The vitamin D receptor binds in a transcriptionally inactive form and without a defined polarity on a retinoic acid response element. FASEB J 1999;13: 1073-1081.

35 Krezel W, Kastner P, Chambon P: Differential expression of retinoid receptors in the adult mouse central nervous system. Neuroscience 1999;89:1291-1300.

36 Mey J, Morassutti DJ, Brook G, Liu RH, Zhang YP, Koopmans G, McCaffery P: Retinoic acid synthesis by a population of NG2positive cells in the injured spinal cord. Eur J Neurosci 2005;21:1555-1568.

37 Kern J, Schrage K, Koopmans GC, Joosten EA, McCaffery P, Mey J: Characterization of retinaldehyde dehydrogenase-2 induction in NG2-positive glia after spinal cord contusion injury. Int J Dev Neurosci 2007;25:7-16.

38 Zhelyaznik N, Mey J: Regulation of retinoic acid receptors alpha, beta and retinoid $\mathrm{X}$ receptor alpha after sciatic nerve injury. Neuroscience 2006;141:1761-1774.

-39 Mangelsdorf DJ, Borgmeyer U, Heyman RA, Zhou JY, Ong ES, Oro AE, Kakizuka A, Evans RM: Characterization of three RXR genes that mediate the action of 9-cis retinoic acid. Genes Dev 1992;6:329-344.

40 van Neerven S, Kampmann E, Mey J: RAR/ RXR and PPAR/RXR signaling in neurologi$\mathrm{cal}$ and psychiatric diseases. Progr Neurobiol 2008;85:433-451.

41 Kephart DD, Walfish PG, DeLuca H, Butt TR: Retinoid X receptor isotype identity directs human vitamin $\mathrm{D}$ receptor heterodimer transactivation from the 24-hydroxylase vitamin D response elements in yeast. Mol Endocrinol 1996;10:408-419.

42 Bugge TH, Pohl J, Lonnoy O, Stunnenberg HG: RXR alpha, a promiscuous partner of retinoic acid and thyroid hormone receptors. EMBO J 1992;11:1409-1418.

43 Corley SM, Tsai S-Y, Wilkins MR, Weickert CS: Transcriptomic analysis shows decreased cortical expression of NR4A1, NR4A2 and RXRB in schizophrenia and provides evidence for nuclear receptor dysregulation. PLoS One 2016;11:e0166944.

44 Fillman SG, Cloonan N, Catts VS, Miller LC, Wong J, McCrossin T, Cairns M, Weickert CS: Increased inflammatory markers identified in the dorsolateral prefrontal cortex of individuals with schizophrenia. Mol Psychiatry 2013;18:206-214.
45 Fillman SG, Sinclair D, Fung SJ, Webster MJ, Weickert CS: Markers of inflammation and stress distinguish subsets of individuals with schizophrenia and bipolar disorder. Transl Psychiatry 2014;4:e365.

46 Zhang Y, Catts V, Sheedy D, McCrossin T, Kril J, Weickert CS: Cortical grey matter volume reduction in people with schizophrenia is associated with neuro-inflammation. Transl Psychiatry 2016;6:e982.

47 Meyer U: Developmental neuroinflammation and schizophrenia. Prog Neuropsychopharmacol Biol Psychiatry 2013;42:20-34.

- 48 Monji A, Kato TA, Mizoguchi Y, Horikawa H, Seki Y, Kasai M, Yamauchi Y, Yamada S, Kanba S: Neuroinflammation in schizophrenia especially focused on the role of microglia. Prog Neuropsychopharmacol Biol Psychiatry 2013;42:115-121.

49 Doorduin J, de Vries EFJ, Willemsen ATM, de Groot JC, Dierckx RA, Klein HC: Neuroinflammation in schizophrenia-related psychosis: a PET study. J Nucl Med 2009;50:18011807.

50 Bloomfield PS, Selvaraj S, Veronese M, Rizzo G, Bertoldo A, Owen DR, Bloomfield MAP, Bonoldi I, Kalk N, Turkheimer F, McGuire P, de Paola V, Howes OD: Microglial activity in people at ultra high risk of psychosis and in schizophrenia: an [(11)C]PBR28 PET Brain Imaging Study. Am J Psychiatry 2016;173:4452.

51 Weickert CS, Sheedy D, Rothmond DA, Dedova I, Fung S, Garrick T, Wong J, Harding AJ, Sivagnanansundaram S, Hunt C, Duncan C, Sundqvist N, Tsai SY, Anand J, Draganic D, Harper C: Selection of reference gene expression in a schizophrenia brain cohort. Aust NZ J Psychiatry 2010;44:59-70.

52 Llewellyn DJ, Lang IA, Langa KM, MunizTerrera G, Phillips CL, Cherubini A, Ferrucci L, Melzer D: Vitamin D and risk of cognitive decline in elderly persons. Arch Int Med 2010; 170:1135-1141.

53 Kim MS, Sweeney TR, Shigenaga JK, Chui LG, Moser A, Grunfeld C, Feingold KR: Tumor necrosis factor and interleukin 1 decrease RXR alpha, PPAR alpha, PPAR gamma, LXR alpha, and the coactivators SRC-1, PGC-1 alpha, and PGC-1 beta in liver cells. Metabolism 2007;56:267-279.

- 54 Denson LA, Auld KL, Schiek DS, McClure $\mathrm{MH}$, Mangelsdorf DJ, Karpen SJ: Interleukin-1 beta suppresses retinoid transactivation of two hepatic transporter genes involved in bile formation. J Biol Chem 2000;275:88358843.

55 Li D, Zimmerman TL, Thevananther S, Lee HY, Kurie JM, Karpen SJ: Interleukin-1 betamediated suppression of RXR:RAR transactivation of the Ntcp promoter is JNK-dependent. J Biol Chem 2002;277:31416-31422. 
-56 Na SY, Kang BY, Chung SW, Han SJ, Ma XJ, Trinchieri G, Im SY, Lee JW, Kim TS: Retinoids inhibit interleukin-12 production in macrophages through physical associations of retinoid X receptor and NF kappa B. J Biol Chem 1999;274:7674-7680.

-57 Kirchmeyer M, Koufany M, Sebillaud S, Netter P, Jouzeau JY, Bianchi A: All-trans retinoic acid suppresses interleukin- 6 expression in interleukin-1-stimulated synovial fibroblasts by inhibition of ERK1/2 pathway independently of RAR activation. Arthritis Res Ther 2008;10:R141.

58 Wojtal KA, Wolfram L, Frey-Wagner I, Lang S, Scharl M, Vavricka SR, Rogler G: The effects of vitamin A on cells of innate immunity in vitro. Toxicol In Vitro 2013;27:1525-1532.

59 Ogata A, Nishimoto N, Shima Y, Yoshizaki K, Kishimoto T: Inhibitory effect of all-trans retinoic acid on the growth of freshly isolated myeloma cells via interference with interleukin-6 signal transduction. Blood 1994;84: 3040-3046.

-60 Fillman S, Weickert T, Lenroot R, Catts S, Bruggemann J, Catts V, Weickert C: Elevated peripheral cytokines characterize a subgroup of people with schizophrenia displaying poor verbal fluency and reduced Broca's area volume. Mol Psychiatry 2016;21:1090-1098.
61 Catts VS, Wong J, Fillman SG, Fung SJ, Weickert CS: Increased expression of astrocyte markers in schizophrenia: association with neuroinflammation. Aust NZ J Psychiatry 2014;48:722-734.

62 Han YF, Cao GW: Role of nuclear receptor NR4A2 in gastrointestinal inflammation and cancers. World J Gastroenterol 2012;18: 6865-6873.

63 Bonta PI, van Tiel CM, Vos M, Pols TWH, van Thienen JV, Ferreira V, Arkenbout EK, Seppen J, Spek CA, van der Poll T, Pannekoek H, de Vries CJM: Nuclear receptors Nur77, Nurr1, and NOR-1 expressed in atherosclerotic lesion macrophages reduce lipid loading and inflammatory responses. Arterioscler Thromb Vasc Biol 2006;26:2288-2294.

64 McMorrow JP, Murphy EP: Inflammation: a role for NR4A orphan nuclear receptors? Biochem Soc Trans 2011;39:688-693.

65 Paillasse MR, de Medina P: The NR4A nuclear receptors as potential targets for anti-aging interventions. Med Hypotheses 2015;84:135140.
66 Chu YP, Kompoliti K, Cochran EJ, Mufson EJ, Kordower JH: Age-related decreases in Nurr1 immunoreactivity in the human substantia nigra. J Comp Neurol 2002;450:203214.

67 Godbout JP, Johnson RW: Age and neuroinflammation: a lifetime of psychoneuroimmune consequences. Immunol Allergy Clin North Am 2009;29:321-337.

68 Gur RE: Left hemisphere dysfunction and left hemisphere overactivation in schizophrenia. J Abnorm Psychol 1978;87:226-238.

69 Hugdahl K, Løberg E-M, Jørgensen HA, Lundervold A, Lund A, Green MF, Rund Br: Left hemisphere lateralisation of auditory hallucinations in schizophrenia: a dichotic listening study. Cogn Neuropsychiatry 2008;13:166179.

70 Angrilli A, Spironelli C, Elbert T, Crow TJ, Marano G, Stegagno L: Schizophrenia as failure of left hemispheric dominance for the phonological component of language. PLoS One 2009;4:e4507.

-71 Marchwicka A, Cebrat M, Laszkiewicz A, Sniezewski L, Brown G, Marcinkowska E: Regulation of vitamin D receptor expression by retinoic acid receptor alpha in acute myeloid leukemia cells. J Steroid Biochem Mol Biol 2016;159:121-130. 